\title{
Implications of comorbidity: lessons from epidemiological studies'
}

\author{
HANS-ULRICH WITTCHEN
}

Max Planck Institute of Psychiatry (Clinical Institute), Clinical Psychology, Munich, Germany

\begin{abstract}
RIASSUNTO. Scopo - Lo studio affronta problemi concettuali, metodologici e clinici della comorbidità, alla luce dei più recenti studi epidemiologici. Inoltre viene valutata la causa potenziale e il ruolo patogenetico dei disturbi temporaneamente primari per la comparsa dei disturbi secondari. Risultati - I risultati disponibili fino ad oggi suggeriscono che la comorbidità (a) non è un artefatto delle strategie di valutazione, del campionamento o del disegno, (b) è specifica nei differenti disturbi, (c) è particolarmente frequente nei disturbi affettivi e d'ansia, (d) influisce sistematicamente sull'andamento delle condizioni di comorbidità e (f) potrebbe essere correlata con modelli di evoluzione dei sintomi. Conclusioni - E inoltre evidente che forme specifiche di disturbi di ansia primaria comportano il rischio di sviluppare disturbi depressivi secondari, aumentano la probabilità di non remissione così come il numero di successivi episodi depressivi.
\end{abstract}

PAROLE CHIAVE; comorbidità, progressione dei sintomi, ansia, disturbi affettivi, disturbi da abuso di sostanze, epidemiologia.

SUMMARY. Objective - The paper discusses conceptual, methodological and clinical issues of comorbidity from the perspective of more recent epidemiological studies. Further the potential causal and pathogenic role of temporally primary disorders for the onset of secondary disorders is evaluated. Results - The available data suggest so far that comorbidity (a) is not an artefact of assessment strategies, sampling or design features, (b) is specific in different disorders, (c) is particularly frequent in anxiety and affective disorders, (d) affects systematically the course of the comorbid conditions and (f) might be related to symptom progression models. Conclusions - Furthermore, evidence is presented that specific forms of primary anxiety disorders affect the risk for secondary depressive disorders, increase the likelihood of non-remission as well as the number of subsequent depressive episodes.

KEY WORDS: comorbidity, symptom progression, anxiety, affective and substance disorders, epidemiology.

Ricevuto il 19.04.96 - Revisione ricevuta il 3.5.1996 - Accettato il 4.5.1996.

\section{INTRODUCTION}

The heuristic value of the comorbidity concept for a better understanding of mental disorders was recog-

Indirizzo per la corrispondenza: Professor H.U. Wittchen, Max Planck Institute für Psychiatrie, Klinisches Institut, Kraepelinstrasse 10,80804 München (Germany).

$\mathrm{Fax}+49$ - 89-3062.2544.

${ }^{1}$ Based on IRGASD (Italian Research Group for Affective and Schizophrenic Disorders) lecture, organised by the Institute of Psychiatry of the University of Verona, and delivered in Verona on December 4th 1995. IRGASD activities carried out under the auspices of Dr. Paul Janssen Medical Institute, are supported by Janssen-Cilag. nized long ago by Hippocrates. Scientific interest in this concept, however, emerged only fairly recently. This increase in attention seems to be significantly related to (a) the introduction of explicit descriptive, operational criteria for specific mental disorders (DSMIII to DSM-IV- American Psychiatric Association, 1980, 1987, 1994, ICD-10 WHO, 1991) and (b) associated shifts of paradigms in psychopathological research (such as the neo-kraepelinian paradigm - Klerman, 1990). Although now frequently used in clinical research and practice as well as epidemiology, the term comorbidity still remains poorly defined and lacks clear conceptualization (Maser \& Cloninger, 1990). This paper briefly discusses critical issues of comorbidity and summarizes more recent epidemiologi- 
cal data concerning the frequency of current and lifetime comorbidity of mental disorders as well as potential pathogenetic and clinical implications. This review is restricted to epidemiological studies focussing on anxiety and affective disorders. Other comorbidity findings for example in relation to other mental disorders, somatic conditions as well as personality disorders will not be discussed.

Some critics have claimed that comorbidity simply might be regarded as an artefact of our current DSMIII-R- and ICD-10-based descriptive diagnostic classification rules and thus reject this concept as useless for pathogenic and clinical purposes. This position is shared particularly by those who prefer traditional nosological models, hierarchical classification schemes or more comprehensive main dimensions of psychopathology (Goldberg, 1996). Others, however, emphasize not only the value of comorbidity for nosological issues, but also stress its more general importance for research and clinical implications. As noted by Regier et al. (1992, p. 2), «comorbidity may modify the clinical course of patients with the same diagnosis by affecting the time of detection, prognosis, treatment selection, and posttreatment outcome of an index diagnosis\%. At this point, however, there are only few data available about the specific pathogenic, therapeutic and prognostic implications of comorbidity (for a more detailed discussion see Wittchen, 1996). But in some areas, such as comorbidity between anxiety and affective as well as substance use disorders, it has at least been clearly demonstrated that the presence of more than one disorder can interfere significantly with the effectiveness of behavioral as well as pharmacological treatments (i.e. Marks, 1985).

Table 1. - Critical issues in the assessment of comorbidity.

\begin{tabular}{|c|c|c|}
\hline 1. Conceptual level: & $\begin{array}{l}\text { a) } \\
\text { b) } \\
\text { c) } \\
\text { d) } \\
\text { e) }\end{array}$ & $\begin{array}{l}\text { comorbidity }=\text { associations between descriptive classes of disorders in } \\
\text { co-occurrence }=\text { cross sectional associations between symptoms or syn } \\
\text { disorders as defined by classification systems } \\
\text { postulated subthreshold models } \\
\text { application of hierarchical rules as suggested by diagnostic systems (i.e }\end{array}$ \\
\hline $\begin{array}{l}\text { 2. Units of content: } \\
\text { (Diagnostic coverage) }\end{array}$ & $\begin{array}{l}\text { a) } \\
\text { b) } \\
\text { c) } \\
\text { d) }\end{array}$ & $\begin{array}{l}\text { Within any (or some) of the following groups: } \\
\text { mental disorders and specific subtypes within disorders } \\
\text { personality disorders } \\
\text { somatic disorders } \\
\text { psychosocial impairments and disabilities or between any of the above }\end{array}$ \\
\hline 3. Time window: & $\begin{array}{l}\text { a) } \\
\text { b) } \\
\text { c) } \\
\text { d) }\end{array}$ & $\begin{array}{l}\text { cross-sectional ( } 2 \text { weeks, I month, } 6 \text { months, etc) } \\
\text { longitudinal ( } 1 \text { year, } 3 \text { years, etc) } \\
\text { lifetime (over the whole lifespan) } \\
\text { accuracy of temporal resolution }\end{array}$ \\
\hline 4. Assessment method: & $\begin{array}{l}\text { a) } \\
\text { b) } \\
\text { c) } \\
\text { d) } \\
\text { e) }\end{array}$ & $\begin{array}{l}\text { unstructured (nosological) diagnoses ICD-9) } \\
\text { loosely structured clinical diagnoses (DSM-III) } \\
\text { structured diagnostic interviews (SCID) } \\
\text { standardized diagnostic interviews (DIS,CIDI) } \\
\text { specific comorbidity instruments (memory probes) }\end{array}$ \\
\hline 5. Design $\&$ analysis & $\begin{array}{l}\text { a) } \\
\text { b) } \\
\text { c) }\end{array}$ & $\begin{array}{l}\text { sampling procedure } \\
\text { correction for base rates } \\
\text { consideration of confounding factors }\end{array}$ \\
\hline
\end{tabular}

6. Explanations of Comorbidity

Artefact hypotheses

* Assessment instruments

* Random

* Help-seeking

* Population

True associations

* Causal

* Common etiology

* Alternative manifestations

* Developmental stages 


\section{CRITICAL ISSUES IN EVALUATING COMORBIDITY}

The first difficulty in determining the implications of comorbidity is the definition and usage of the term itself. Wittchen (1996) notes that there are multiple definitions of comorbidity, making direct comparisons of studies sometimes difficult. Besides definitions which use the term within the context of nosological considerations (Feinstein, 1970), more adequate definitions of comorbidity can be derived from Boyd et al. (1984) defining comorbidity from an epidemiological perspective «as the relative risk of a person with one disorder to have another disordery as well as more comprehensively by Burke et al. (1990). The latter defined comorbidity "as the presence of more than one specific disorder in a person in a defined period of time». This general definition provides information regarding what is being measured (disorders and not illnesses): it is applicable for longitudinal, lifetime as well as cross-sectional measurements and it covers all possible conceptual frameworks. Therefore, it can be applied to many of the more recent epidemiological and clinical studies studying the frequency and the meaning of cooccurrences of different diagnostic classes, defined in ICD-10 or DSM-IIIR.

A number of other factors complicate the interpretations of comorbidity findings (Table I):

1. Symptoms, syndromes or disorders. Comorbidity in many publications is sometimes used to refer to associations between symptoms and syndromes rather than co-occurrences of specific diagnostic classes of codified disorders in ICD-10 or DSMIII-R disorders. This has led to considerable confusion, especially when the diagnostic rules are not clearly specified. As useful as this symptom and syndrome approach might be in studies of clearly defined subthreshold conditions, as well as the determination of course patterns, for the concept of comorbidity it has led to confusion.

2. Number of diagnoses considered. Furthermore studies often differ with respect to the number of disorders they take into consideration, compromising their comparability to other studies when looking into the frequency and the patterns of comorbid conclusions. For example, there is little comparability in the specific subtypes of anxiety as well as substancespecific abuse and dependence diagnoses. In the case of anxiety disorders, for example, no epidemiological study included posttraumatic stress disorder (except for Kessler et al., 1994), separation anxiety disorder, adjustment disorders with anxious mood or atypical forms of these disorders. For substance use disorders, studies vary with regard to the type of substance included, most leave out nicotine dependence completely, substance-specific comorbidity patterns are: rarely reported, and most studies have limited analyses to alcohol use disorders. Furthermore, there are almost no studies that control comorbidity findings for substance-induced mental disorder that might explain a substantial proportion of artefactual comorbidity.

3. Comorbidity between axes. Generally comorbidity can be considered between different forms of mental disorders and specific subtypes within one group of disorders, between personality disorders, somatic disorders and psychosocial impairments and disabilities or between any of these groups.

4. Time window. The «time window» under consideration is another factor influencing findings. Results of comorbidity have to be clearly differentiated, whether they depend upon cross-sectional (2 weeks, 1 month, 6 months, etc.), longitudinal (1 year, 3 years, etc.) or lifetime (over the whole life span) assessment of symptoms or syndromes, resulting in different prevalences and different patterns of comorbidity. Further difficulties arise in the accuracy of resolution when determining which disorder is primary or secondary, because of questionable validity of retrospectively assessed age of onset information for each disorder.

5. Instrument effects. The method of diagnostic and comorbidity assessment and the derivation of specific diagnoses are another critical area. A WHO collaborative study (Wittchen, 1996) found that standardized instruments usually generate 2-3 times as many diagnoses as assigned by a clinician, who tends to summarize features of several diagnoses under one principal diagnosis as well as neglects past and lifetime diagnoses not present at the time of the investigation. However, even if there is agreement on the use of a specific standardized diagnostic tool, the instrument can be used differently. Studies often differ, for example, in the way DSMIII-R hierarchy rules (exclusion rules criteria) are applied, significantly affecting the resulting prevalence rates. Furthermore, studies using the CIDI frequently differ with regard to the diagnostic sections covered. Many do not evaluate all anxiety or soma- 
toform disorders covered by this instrument, resulting in considerably lower comorbid frequencies.

6. Design differences are another significant source of discrepancies in comorbidity rates. Crosssectional, follow-up and longitudinal designs as well as age cohort studies obviously affect comorbidity findings simply by covering different time periods of risk. Further differences become evident when looking at different sampling strategies. Studies in clinical settings usually reveal twice as high rates of comorbidity as compared to those found in the general population (Wittchen \& Essau, 1989; Wittchen et al., 1991). This might reflect the fact that those with multiple disorders are more likely to seek help and receive treatment (Helzer \&" Pryzbeck, "1988) and underlines the general characteristics of all clinical samples to be highly selective in the clinical patterns. Therefore, epidemiological studies based on community samples are probably more likely to provide a representative view of comorbidity patterns that is unbiased in terms of selective effects.

\section{FREQUENCY OF COMORBIDITY IN EPIDEMIOLOGICAL STUDIES}

Most epidemiological surveys in the past 15 years have used a standardized diagnostic interview (mostly Diagnostic Interview Schedule, DIS - Ro- bins et al., 1982, or the WHO-Composite International Diagnostic Interview, CIDI, or modifications thereof - Wittchen, 1994) based on explicit diagnostic criteria. Despite some degree of methodological differences these studies conclude that about $50 \%$ of all cases have more than one disorder in their lifetime, with almost one third having comorbid conditions in the past twelve months (Kessler et al., 1994: Merikangas et al., 1996). These studies also confirmed, by using appropriate statistical measures (odds ratio), that these comorbidity rates can not been explained by chance or regarded as an artefact by sampling or instrumentation (see British Journal of Psychiatry, vol. 168, Suppl. 30, 1996). In the following three paragraphs some selected findings will be presented that might demonstrate specifically the potential etiopathogenic and clinical importance of comorbidity.

\section{Anxiety disorders: lessons from epidemiological studies}

Three examples have been selected for this area: symptom progression, the pathogenic importance of early versus late panic attacks, and suicide attempts.

From the Study of Comorbidity to the Study of Symptom Progression: The majority of studies focussed on anxiety disorders that have been shown to be significantly associated (a) among each others (Magee et al., 1996), with lifetime Odds ratios ran-

Table II. - Comorbidity of anxiety disorders with depressive (lifetime and 12-month) and substance use disorders in a prospective longitudinal (MFS) (Wittchen et al., 1992) and a cross-sectional study (NCS) (Kessler et al., 1994).

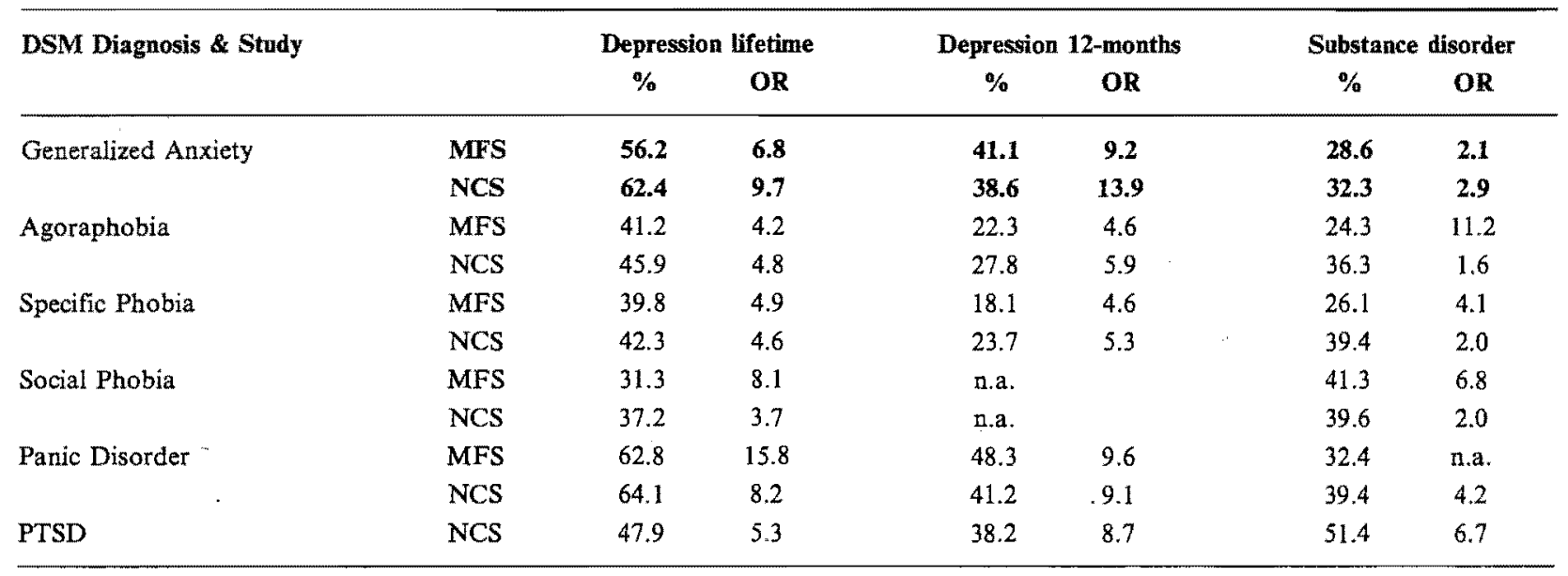

n.a.: data not available

(from Wittchen \& Vossen, 1995) 


\section{Symptom}

occurence spontaneous panic

recurrent panic attacks

subsequent avoidance behavior

expectation anxlety

demoralization

self-help strategies

\section{Precursor/Consequence}

\author{
biological vulnerability \\ cognitive vulnerability
}

sensitization

Panic disorder

Agoraphobia

(Generalized Anxiety disorder)

Major Depression

Substance Abuse

Figure 1. - Symptom progression: from panic to depression.

ging from 3.8 (social phobia and GAD) to as high as 12.3 (GAD and panic disorder) as well as (b) with other mental disorders. As an example for these findings table II compares the findings of a prospective longitudinal 7-years study (Wittchen \& Von Zerssen, 1987) with the more recent findings from the cross-sectional National Comorbidity Survey (NCS - Kessler et al., 1994). Although these two studies were conducted in different countries, with slightly different diagnostic instruments, different diagnostic systems (DSM-III and DSM-III-R) and are hardly comparable with regard to sample size (NCS more than 8000 respondents, MFS only 1366 subjects) there is surprisingly high agreement. Particularly strong associations (Odds) are evident for current and lifetime affective disorders, with generalized anxiety disorders and panic disorders. Considerably lower but still significant odds ratios were found for substance disorders.

The strong interest in anxiety disorders was probably stimulated by two interrelated facts. One is the finding that panic attacks and simple and social phobias usually start early in adolescence and thus could be considered a primary disorders, the other is the suggestion of so-called symptom progression models (SPM).

Such models (figure 1) suggest a systematic progression (for example Klein, 1981) from an initial spontaneous panic attack to the development of agoraphobia, expectation anxiety (GAD) to demoralization (Major depression) and helpseeking (substance abuse). Similar models have recently developed for pathways from phobias into depression (Wittchen \& Vossen, 1995). Retrospective analyses from cross-sectional studies as well as the few available longitudinal epidemiological studies (Angst et al., 1990) have provided some evidence for such pathways, including the demonstration that panic attacks frequently precede the development of agoraphobia, as well as that anxiety disorders usually precede depressive and substance use disorders (Merikangas et al., 1996). Furthermore, we could recently demonstrate that primary anxiety disorders affect significantly the length of depressive episodes and the number of subsequent depressive episodes over an observation period of seven years (Wittchen \& Vossen, 1995).

Different pathogenic mechanisms in late versus early onset panic: Based on findings suggesting that symptom progression might be different in subjects with a typical, relatively early age of first onset in late adolescence and early adulthood and those with a later onset in life (Burke et al., 1990), we recently subtyped subjects according to this bimodal age of onset distribution into early (first onset prior to 
age of 25) and late onset panicers (after age of 25). When examining their spontaneous course of illness over 7 years we found: 1) a significantly higher symptom score for late onset panic attacks due to more frequent symptoms related to the respiratory and cardiac system as well as fear of dying, (2) a considerably elevated risk for developing multimorbidity (having affective and substance and somatoform disorders) in the late onset group and (3) a significantly more rapid development of secondary disorders in the late onset group. In the early onset group usually years went by before the development of secondary disorders (4) Further the early onset group had considerably higher odds to develop agoraphobia as well as other phobias. Wittchen \& Perkonigg, submitted for publication).

Comorbidity, suicidal ideation and suicide attempts: Most studies in suicide research have been focussing on the relationship with depressive disorders. Only recently, stimulated by more sophisticated analyses of epidemiological datasets (Weissman et al., 1989) the critical role of comorbidity specifically with anxiety disorders was examined. These studies showed that cases with pure major depression have no or only slightly elevated odds for suicide attempts as compared to subjects with no mental disorders, whereas lifetime anxiety disorders comorbid with depressive disorders, and particularly those with panic attacks, have highly elevated odds for suicide attempts.

\section{Depressive disorders: lessons from epidemiological studies}

There are a fairly large number of epidemiological studies that have documented high comorbidity rates in depressive disorders. Few studies have, however gone beyond by examining temporal relationship and other implications of this comorbidity. One of the most detailed studies is the NCS. Kessler et al. (1996) recently demonstrated (Table III) on the basis of his assessment with the UM-CIDI, by taking into account various anxiety disorder (including PTSD), substance use disorders (excluding nicotine dependence) as well as dysthymia and conduct disorder, that only few major depressive disorders are pure; $26.0 \%$ of his general population sample aged 15 to 55 had a pure lifetime depressive disorder, with only few of the comorbid cases having a primary depressive disorder. Based on discrete-time sur- vival models in which information about age of onset was used to study the time-lagged effects of earlier disorders on the subsequent onset of secondary depression the authors found:

(1) $67.9 \%$ of cases with secondary depression are associated with a temporal primary anxiety disorder, $19.2 \%$ with primary substance use disorder and $1.8 \%$ with primary dysthymia and $12.6 \%$ with primary conduct disorder.

(2) The average difference between onset were very short for GAD and panic disorder, suggesting that these anxiety disorders are fairly quickly followed by depression (average of 1.5 years). Considerably longer time intervals were found for primary agoraphobia (10.6 years), primary simple phobia (13.6 years) as well as conduct disorder (11.8 years). Primary substance use disorder precede secondary depression on average by 4.3 to 6.5 years, depending of the substance.

(3) Primary anxiety disorders also significantly increase the odds of a more persistent course of depression and are also clearly related to higher self-perceived interference with life and activities, suicide attempts and hospitalization.

(4) Primary substance use disorders are associated with interference and hospitalization but not with suicide attempts.

Table III. - Prevalences of lifetime pure, primary and secondary major depressive disorders with standard errors.

\begin{tabular}{lllllll}
\hline & \multicolumn{2}{c}{ Pure } & \multicolumn{2}{c}{ Primary } & \multicolumn{2}{c}{ Secondary } \\
& $\%$ & SE & $\%$ & SE & $\%$ & SE \\
\hline Total & 26.0 & 2.5 & 12.2 & 1.2 & 61.8 & 2.6 \\
Women & $30.1^{*}$ & 3.0 & 12.2 & 1.6 & $57.7^{*}$ & 2.9 \\
Men & 18.6 & 2.7 & 12.1 & 2.2 & 69.3 & 3.4 \\
\hline
\end{tabular}

\# respondents with lifetime MDD and lifetime dysthymia only were coded as pure

* $p<0.05$ women versus men

(from Kessler et al.,1996)

These data for the first time confirmed with more sophisticated statistical analyses earlièr assumptions and observations (Wittchen \& von Zerssen, 1987; Wittchen \& Vossen, 1995) about the effect of comorbidity in depressive disorders. But of course it should be mentioned that these analyses are derived from retrospective data from cross-sectional study and await further validation in prospective studies. 
Substance use disorders: lessons from epidemiological studies

There is agreement between the two major USAmerican studies, the NCS and the ECA that (1) over half $(51.4 \%$ : NCS; $53.1 \%$ : ECA) of those with any substance use disorder have experienced other forms of mental disorders at some time in their life. (2) Approximately $36.6 \%$ of those with any lifetime alcohol use disorder experienced some mental disorder at some time in their life, a rate which is more than double that found in those without an alcohol disorder. (3) Furthermore, respondents with alcohol or drug dependence were more likely to suffer from a comorbid (either lifetime or 1-year) psychiatric disorder than those with alcohol or drug abuse. (4) Major depression was often evident in those with alcohol or drug dependence although it remains unclear which of these disorders came first and which second. (5) Slightly higher associations were found for anxiety disorders, with phobia as the most prevalent and $\mathrm{GAD}$ and panic disorder demonstrating the strongest association. (6) Adolescent conduct disorder and adult antisocial personality disorder distinctly stand out as being very frequently found in those with substance use disorders - across both substance abuse and dependence. (7) PTSD is strongly related only to drug dependence but not abuse nor alcohol dependence. (8) Mania and schizophrenia. have both a strong and consistent relationship to alcohol as well as drug dependence, but not to abuse (Wittchen et al., 1996).

Most of these findings and conclusions have been replicated in other studies such as the MFS (Wittchen et al., 1992), the Zurich cohort study (Angst et al., 1990) or the epidemiological study in Edmonton, Canada (Russel et al., 1994).

Time sequence: What comes first? In terms of the potential causal role of other mental disorders as risk factors for substance use disorders it is of special interest to investigate the order in which disorders develop over life. In the vast majority of respondents of the above mentioned studies the onset of other mental disorders clearly preceded the onset of the substance use disorder. This sequence effect was especially strong and consistent for conduct disorder and anxiety disorders and least strong (and even reversed in men) for affective disorders, schizophrenia, mania and PTSD.

Affective disorders in both the ECA and the NCS occurred at an almost equal frequency either before or after the onset of the substance use disorder. $48.4 \%$ of comorbid respondents reported the affective disorder occurred first, $40.3 \%$ reported that the substance use disorder occurred clearly before. the onset of the affective disorder.

On the other hand, $79.3 \%$ of substance use-/anxiety disorder comorbid. cases reported that their anxiety disorder started first while only $16.6 \%$ reported that the substance use disorder started first. The effect for conduct disorder (and antisocial personality disorder) was even stronger, $89.3 \%$ reporting that the conduct or antisocial personality disorder began first and only $7.5 \%$ reporting that their substance use disorder began first. For comorbidity within the substance use disorders, the ECA further indicated on the symptom level that win $43.3 \%$ of comorbid cases the age of onset for the first alcohol problem was lower than the age of first drug problem; in $36.1 \%$ the age of the first drug problem was lower than the age of first alcohol problem» (Anthony \& Helzer, 1991, p.148).

This suggests that mental disorders, particularly conduct and anxiety disorders, might play an important pathogenic role in the development of the subsequent substance use disorder, but Kessler et al. (in preparation) warn that «it is important to recognize that neither temporal order nor prediction can be taken to imply causal priority". They point out that a temporally prior disorder may either directly or indirectly influence the development of a later disorder, or a third variable may be the causal variable in causing comorbid disorders.

\section{CONCLUSIONS}

The above cited selected findings have underlined the usefulness of the comorbidity concept as a new way of looking into the longitudinal and developmental aspects of mental disorders. Furthermore it has become evident that the comorbidity concept might have implications simply documenting the current overlap of conditions and requires more sophisticated design and statistical models than previously thought. The full exploration of mechanisms of comorbidity requires (a) more syndrome-focussed prospective longitudinal studies and (b) an interdisciplinary approach to investigate nosology, assessment and underlying models of comorbidity. In this respect study designs are needed that are partially be- 
yond the scope of more traditional clinical and epidemiological studies which comprise so far the bulk of comorbidity research. Family (Merikangas, 1990; Maier et al., 1994) and twin studies (Kendler, 1996; Andrews, 1996) as well as experimental tests of hypotheses in random subsamples of high-risk probands sampled from epidemiological studies might be most important tools.

Similar to the few available prospective longitudinal epidemiological studies they can distinguish between several of the above sources of comorbidity. Furthermore, prospective studies can examine more precisely the longitudinal stability, the order of onset of disorders (Wittchen \& Essau 1989; Angst et al., 1990; Caron \& Rutter, 1991), and thus unravel different pathways into several conditions of psychopathology. In light of the tremendous variability of findings with regard to biological parameters a more precise specification of comorbidity patterns might also be a helpful strategy to identify more specific common biochemical markers relevant in the aetiology of specific mental disorders as well as comorbid conditions.

But several caveats for epidemiological surveys of comorbidity phenomena should also be addressed. The danger of premature artefactual explanations of comorbidity for example between substance use disorder and other forms of mental disorders becomes evident if we take into account that substance use might not only be used by the respondents to minimize psychiatric symptomatology (the use of substances as a form of 'self-medication') (Stockwell et al., 1983), but also that the long-term use of certain substances (for example alcohol) can lead to symptoms of depression and anxiety. At this point almost no published epidemiological data are available to determine in detail these alternative explanations.

Which model fits best? We should keep in mind that there are numerous possible mechanisms involved in comorbidity. To discuss those more concretely we focus on substance use comorbidity:

\section{- Disorder A Predisposes to Disorder $B(A \Rightarrow B)$}

A primary disorder may directly predispose to the development of a secondary disorder. In a first example a person with a childhood onset of social phobia might have used alcohol or tobacco for alleviating stress-related symptoms in social situations, slipping after years into patterns of abuse or dependence. This pattern has recently been found by
Wittchen \& Beloch (submitted for publication). Vice versa, substance use disorders can raise the likelihood for developing a mental disorder. Rosen \& Kosten (1992) found that cocaine use can precipitate panic disorder in patients with no previous history of panic attacks. Cottler et al. (1992) also found in their study that drug users experienced more traumatic events - and were more likely to meet criteria for PTSD in later life. The ECA and NCS have both asked respondents to retrospectively assess the onset of their symptoms and found that some disorders precede the onset of others, however, there is the danger of a retrospective recall bias. In a study which aimed to minimize this recall bias by asking younger people about the onset of their disorders, Christie et al. (1988) found that in almost $75 \%$ of the young respondents in their sample, anxiety or depressive disorder clearly began before the substance use disorder, suggesting that the mental disorder was 'causal' in the development of the substance use disorder. Other examples include agoraphobia developing after the onset of panic disorder as a result of the disabling fear of attacks in situations where help is unavailable and escape is impossible (Klein et al, 1987). This disabling picture of panic and agoraphobia avoidance has been found to be significantly related to the subsequent development of benzodiazepine abuse (Wittchen \& von Zerssen, 1987) or chronic mixed anxiety-depression, which can occur when unremitting chronic anxiety leads to feelings of hopelessness and helplessness (Akiskal, 1990), resulting in full major depressive episodes (see below).

Either $A$ or $B$ May Predispose to the Other $(A \Leftrightarrow B)$

It is also possible that either of two disorders predisposes to the development of the other. One of the strongest comorbidity associations has been found for substance use disorders with comorbid conduct disorders or antisocial personality disorder (Kessler et al., 1996). Here evidence suggests that conduct disorder most frequently can cause substance use disorder, but vice versa substance use disorders can also trigger antisocial personality disorders, such as in cocaine or heroin dependence (criminal acts in order to get the substance), although there is less evidence of this last association being the predominant picture when conduct disorder is being controlled for (Kessler et al., in preparation). Other examples are provided by «self-medication» in anxiety. Substance use and abuse may develop as a means of self-medicating behavior to cope with anxiety symptoms: 


\section{H.U. Wittchen}

long-term use of substances in turn can lead to increased anxiety levels (Kushner et al., 1990).

- A Key Antecedent Factor Is. Specific to Different Disorders $(X \Rightarrow \mathrm{A}$ or $\Rightarrow$ or $\Rightarrow \mathrm{C}$ )

One factor may cause different disorders with different probabilities. For example the occurrence of spontaneous panic attacks (as a key feature in panic disorder) could be regarded as one key antecedent factor not only for the development of panic disorder, agoraphobia or other anxiety disorders, but also as an more general indicator for an assumed vulnerability that puts subjects at risk for developing several severe forms of mental disorders as well as substance use disorders. Models of this type have been proposed as «symptom progression models» by Klein et al. (1987) or Wittchen \& Vossen (1995). Other examples include personality disorders such as conduct disorder. Personality features of conduct disorder or in later age of antisocial personality can lead to earlier usage and dependence of drugs as well as other forms of mental disorders (depression, psychotic disorders). In one example of such an investigation, Nace et al. (1991) found at a syndromal level of analysis that subjects with personality disorder were more extensively involved in substance abuse and differed in their patterns of alcohol use.

- One or More Antecedent Factors Predispose to Distinct Disorders $(X+Y \Rightarrow \mathrm{A}, \mathrm{X}+\mathrm{Z} \Rightarrow \mathrm{B})$

For this pathway, biological, social and cognitive factors have been hypothesized to act as general vulnerability factors $(X)$ that may lead in case of the event $\mathrm{Y}$ or $\mathrm{Z}$ to the development of disorder $\mathrm{A}$ or B. Kessler et al. (in press) recently proposed from a. sociological perspective that «common causes of different psychiatric disorders, such as community context, stress and lack of social support lead to comorbidity (National Institute of Mental Health, 1993)) (p. 11). In its more general form this fourth pattern resembles most closely the many «vulnerability stress models» suggested for headache, psychotic disorder as well as affective disorders.

Other types of antecedent factors are genetic predisposition and vulnerability markers. Dinwiddie \& Reich's (1993) review of family genetic studies led them to conclude that alcoholism and other substance dependence run in families. Furthermore, there is strong evidence for genetic factors playing a role in alcoholism and weaker though considerable evidence for genetic factors in other forms of substance dependence (Merikangas et al., 1992). Fa- milial associations between alcoholism and certain anxiety syndromes (most notably agoraphobia) are also evident (Dinwiddie \& Reich, 1993; Wesner, 1990). Ingraham \& Wender (1992) found a significantly greater incidence of affective disorders and substance abuse in the biological relatives of adoptees with' affective disorders. Furthermore, this was dependent upon sex; female relatives of those with affective disorders were at greater risk for affective disorders while males were at greater risk for substance abuse. Luthar et al. (1992) studied the siblings of opioid addicts and ascertained that these siblings were at high risk for the development of various disorders, particularly ASPD and substance abuse. The presence of a major psychiatric disorder further increased (above the risk already afforded by being a sibling of an addict) their risk of developing substance abuse.

Table IV. - Possible risk/protective factors.

\begin{tabular}{|c|c|}
\hline $\begin{array}{l}\text { Stable susceptibility } \\
\text { and protective factors }\end{array}$ & $\begin{array}{l}\text { Transient precipitative } \\
\text { or supportive factors }\end{array}$ \\
\hline Heritable genetic factors & $\begin{array}{l}\text { genetic (genes expressed at } \\
\text { specific ages) }\end{array}$ \\
\hline $\begin{array}{l}\text { Acquired biological factors } \\
\text { (trauma, toxicity) }\end{array}$ & $\begin{array}{l}\text { nongenetic biological factors } \\
\text { (toxins, weight loss, illness) }\end{array}$ \\
\hline $\begin{array}{l}\text { Familial psychosocial factors } \\
\text { (social learning, conditioning) }\end{array}$ & $\begin{array}{l}\text { psychosocial factors (psycho- } \\
\text { dynamic, sociocultural, condi- } \\
\text { tioning, cognitive) }\end{array}$ \\
\hline
\end{tabular}

Nonfamilia psychosocial factors (individuat experience)

(from Wittchen, 1996)

It is most likely that no single explanation suffices for an explanation of comorbidity in general; rather a number of these paths to comorbidity might play a role which additionally may vary from disorder to disorder. The path to comorbidity that is followed is likely to depend not only on the type of primary disorder but also a variety of other factors (see table IV).

Reservations against comorbidity: So why has the comorbidity approach been challenged several times in the literature? One reason is probably that the term comorbidity has been misleading for many clinicians because it incorporates the word morbus, associated with the medical illness model and nosological considerations (Van Praag, 1996). However, it actually addresses in the field of mental disorders primarily descriptive classes of disorders (thus a better term would be co-disorder). Clinicians educated in the ba- 
sis of the traditional classification models for psychiatric disorders (such as ICD-9) usually find it difficult to switch from the more hierarchical nosological illness model to the more descriptive «atheoreticaly classification schemes characteristic of DSMIIIR and the new ICD-10. While the traditional models have laid emphasis on the current state and principal diagnoses in a more hierarchical way (organic psychoses, psychosis, neurosis, addiction personality disorders, adjustment disorders), the modern classification schemes for mental disorders deleted many of the hierarchical rules and nosological implications, emphasizing that most diagnoses require assessment of symptoms and syndromes over the whole life span in a descriptive way. This necessarily results not only in a substantially higher number of possible diagnoses in the classification schemes, but also, due to the explicit diagnostic criteria and lack of hierarchical diagnostic rules, in a higher number of diagnoses per patient. This descriptive lifetime approach of classifying specific disorders instead of broader conceptionally assumed zillnesses" has increased the notoriously low reliability and ultimately - as is hoped - will also improve the validity of diagnoses of mental disorders. At the same time it has brought the field, particularly in the area of affective-, anxiety- and substance disorder research, closer to the current basic research paradigms in neurobiology and experimental as well as cognitive psychology. It furthermore matches more closely the principles of the functional diagnostic approach in behavior therapy that takes into account the lifelong (learning and problem) history of a case.

Another source of reservations expressed against the new classification schemes and comorbidity, as well as the diagnostic instruments supporting the rigorous derivation of diagnoses and comorbidity patterns, stem from the lack of data supporting the clinical usefulness for prevention, treatment and rehabilitation. Despite many hints that comorbidity might be a useful concept for research and particularly the identification of causal and pathogenic pathways, there is at this point still a lack of coherent theoretical models allowing an integration of comorbidity findings. Thus the treatment and management implications of comorbidity necessarily are highly speculative and poorly supported by data at least in the field of substance dependence and therapeutic interventions. In the field of anxiety disorders (review: Wittchen \& Vossen, 1995) and more recently also in the field of affective disorders (Regier et al.,
1990), however, comorbidity concepts have helped not only to sharpen the structure of therapeutic interventions but also contributed to an increased effectiveness.

For the field of substance use disorders, the clinical utility of comorbidity considerations still remains to be tested. We have given a couple of examples of how and in what areas this step of further exploration is currently being taken. Most of these steps mean sorting out the (causative) pathogenetic pathways in which specific mental disorders are interrelated. Prospective longitudinal epidemiological and family genetic studies, preferably in epidemiological samples, will probably be an essential first step to resolve some of these issues. They will allow in the next step, along with studies in clinical samples, to determine how comorbidity affects the clinical course and ultimately the effectiveness of treatment strategies.

\section{REFERENCES}

Akiskal H.S. (1990). Toward a clinical understanding of the relationship of anxiety and depressive disorders. In Comorbidity of Mood and Anxiety Disorders (ed. J.D. Maser and C.R. Clonin" ger). American Psychiatric Press: Washington.

American Psychiatric Association (1980). Diagnostic and Statistical Manual of Mental Disorders (3rd. ed.). American Psychiatric Association: Washington DC.

American Psychiatric Association (1987). Diagnostic and Statistical Manual of Mental Disorders (3rd. ed. revised). American Psychiatric Association: Washington DC.

American Psychiatric Association (1994), Diagnostic and Statistical Manual of Mental Disorders (4th ed.). American Psychiatric Association: Washington DC

Andrews G. (1996). Comorbidity and the general neurotic syn* drome. British Journal of Psychiatry 168, Suppl. 30, 67-75.

Angst J., Vollrath M., Merikangas K.R. \& Ernst C. (1990). Comorbidity of anxiety and depression in the Zurich Cohort Study of young adults. In Comorbidity of Mood and Anxiety Disorders (ed. J.D. Maser and C.R. Cloninger), pp 123-153. American Psychiatric Press: Washington DC.

Antony J.C. \& Helzer J.E. (1991). Syndromes of drug abuse and dependence. In Psychiatric Disorders in America: the Epidemiologic Catchment Area Study (ed. L.N. Robins and D.A. Regier), pp 116-154. Free Press: New York.

Boyd J.H., Burke J.D., Gruenberg E. et al. (1984). Exclusion criteria of DSM-III: A study of co-occurrence of hierarchy-free syndromes. Archives of General Psychiatry 41, 983-989.

Burke J.D., Wittchen H.U., Regier D.A. \& Sartorius N. (1990). Extracting information from diagnostic interviews on co-oc currence of symptoms of anxiety and depression. In Comorbidity of Mood and Anxiety Disorders (ed. J.D. Maser and C.R. Cloninger), pp 649-668. American Psychiatric Press: Washington DC 


\section{H.U. Wittchen}

Caron C. \& Rutter M. (1991). Comorbidity in child psychopathology: concepts, issues, and research strategies. Journal of Child Psychology and. Psychiatry 32, 1063-1080.

Christie K.A., Burke J.D., Regier D.A., Rae D.S., Boyd J.H. \& Locke B.Z. (1988). Epidemiologic evidence for early onset of mental disorders and higher risk of drug abuse in young adults. American Journal of Psychiatry 145, 971-975.

Cottler L.B., Compton W.M., Mager D., Spitznagel E.L. \& Janca A. (1992). Posttraumatic stress disorder among substance users from the general population. American Journal of Psychiatry $149,664-670$.

Dinwiddie S.H. \& Reich T. (1993) Genetic and family studies of psychiatric illness and alcohol and drug dependence. Journal of Addictive Diseases 12, 17-27.

Feinstein A.R. (1970). The pre-therapeutic classification of comorbidity in chronic disease. Journal of Chronic Diseases 23, 455-468.

Goldberg D. (1996). A dimensional model for common mental disorders. British Journal of Psychiatry 168, Suppl. 30, 35-40.

Helzer J.E. \& Pryzbeck T.R. (1988). The co-occurrence of alcoholism with other psychiatric disorders in the general population and its impact on treatment. Journal of Studies on Alcohol 49, 219-224.

Ingraham L.J. \& Wender P.H. (1992). Risk for affective disorder and alcohol and other drug abuse in the relatives of affectively ill adoptees. Journal of Affective Disorders 26, 45-52.

Kendler K.S. (1996). Major depression and generalized anxiety disorder. Same genes, (partly) different environment - revisited. British Journal of Psychiatry. 168, Suppl. 30, 59-66.

Kessler R.C., McGonagle K.A., Zhao S., Nelson C.B., Hughes M., Eshleman S., Wittchen H.U. \& Kendler K.S. (1994). Lifetime and 12-month prevalence of DSM-III-R psychiatric disorders in the United States: Results from the National Comorbidity Survey. Archives of General Psychiatry 51, 8-19.

Kessler R.C., Nelson C.B., McGonagle K.A., Liu J., Swartz M. \& Blazer D.G. (1996). Comorbidity of DSM-III-R major depressive disorder in the general population: results from the US National Comorbidity Survey. British Journal of Psychiatry 168, Suppl. 30, 8-21.

Kessler R.C., Nelson C.B., McGonagle K.A., Edlund M.J., Frank R.G. \& Leaf P.J. (in press). The epidemiology of co-occurring mental disorders and substance use disorders in the National Comorbidity Survey: Implications for prevention and service utilisation. American Journal of Orthopsychiatry,

Kessler R.C., Edlund M.J., Frank R.G., Kendler K.S., Leaf P.J., Nelson C.B. \& Wittchen H.U. (submitted for publication). Comorbidity of DSM-III-R mental disorders and substance disorders in the National Comorbidity Survey. Bulletin of the Menninger Clinic.

Klein D.F. (1981). Anxiety reconceptualized. In Anxiety: New Research and Changing Concepts (ed. D.F. Klein and J.G. Rabkin). Raven Press: New York.

Klein D.F., Ross D.C. \& Cohen P. (1987). Panic and avoidance in agoraphobia. Archives of General Psychiatry 44, 377-385.

KJerman G.L. (1990) Approaches to the phenomena of comorbidity. In Comorbidity of Mood and Anxiety Disorders. (ed. J.D. Maser and C.R. Cloninger), pp. 13-40. American Psychiatric Press: Washington DC

Kushner M.G., Sher K.J. \& Beitman B.D. (1990). The relation between alcohol problems and the anxiety disorders. American Journal of Psychiatry 147, 685-695.

Luthar S.S., Anton S.F., Merikangas K.R. \& Rounsaville B.J. (1992). Vulnerability to substance abuse and psychopathology among siblings of opioid abusers. Journal of Nervous and Mental Disease 180, 153-161.

Magee W.J., Eaton W.W., Wittchen H.U., McGonagle K.A. \& Kessler R.C. (1996). Agoraphobia, simple phobia, and social phobia in the National Comorbidity Survey. Archives of Ge neral Psychiatry 53, 159-168.

Maier W., Lichtermann D. \& Minges J. (1994). The relationship between alcoholism and unipolar depression. A controlled family study. Journal of Psychiatric Research 28, 303-317.

Marks I.M. (1985). Behavioral psychotherapy for anxiety disorders. In The Psychiatric Clinics in North America: Anxiety Disorders (ed. G.C. Curtis, A. Thyer and J.M. Rainey). Saunders: Philadelphia.

Maser J.D. \& Cloninger C.R. (ed.) (1990). Comorbidity of Mood and Anxiety Disorders. American Psychiatric Press: Washington DC.

Merikangas K.R. (1990). The genetic epidemiology of alcoholism. Psychological Medicine 20, 11-12.

Merikangas K.R., Rounsaville B.J. \& Prusoff B.A. (1992). Familial factors in vulnerability to substance abuse. In Vulnerability to Drug Abuse (ed. M.D. Glantz and R. Pickens), pp 75-97. American Psychological Association: Washington DC.

Merikangas K.R., Angst J., Eaton W.W., Canino G., Rubio-Stipec M., Wacker H., Wittchen H.U., Andrade L., Essau C.A., Kraemer H., Robins L.N. \& Kupfer D.J. (1996). Comorbidity and boundaries of affective disorders with anxiety disorders and substance misuse: results of an international task force. British Journal of Psychiatry 168, Suppl, 30, $49-58$.

Nace E.P., Davis C.W. \& Gaspari J.P. (1991). Axis II comorbidity in substance abusers. American Journal of Psychiatry 148, 118 120.

National Institute of Mental Health (1993). The prevention of mental disorders: A National Research Agenda (unpublished report).

Regier D.A., Burke J.D. \& Burke K.C. (1990). Comorbidity of Affective and Anxiety Disorders in the NIMH Epidemiologic Catchment Area Program. American Psychiatric Press: Washington DC.

Regier D.A., Farmer M.E. \& Goodwin F.K. (1993). Comorbidity of mental and substance abuse disorders. In Psychiatry (ed. R. Michel, A.M. Cooper, S.B. Guze, L.L. Judd, A.J. Solnit, A.J. Stunkard, M.M. Weissman and P.J. Wilner), pp. 1-23. Lippincott: Philadephia.

Robins L.N., Helzer J.E., Ratcliff K.S. \& Seyfried W. (1982). Validity of the Diagnostic Interview Schedule, version II: DSMIII diagnoses. Psychological Medicine 12, 855-870.

Rosen M.I. \& Kosten T. (1994). Cocaine-associated panic attacks in methadone-maintained patients. American Journal of Drug and Alcohol Abuse 18, 57-62.

Russell J.M., Newman S.C. \& Bland R.C. (1994). Drug abuse and dependence. Acta Psychiatrica Scandinavica, Supplementum No. 376, 54-62.

Stockwell T., Stnail P., Hodgson R. \& Canter S. (1983). Alcohol dependence and phobic anxiety states II: retrospective study. British Journal of Psychiatry 144, 58-63.

VanPraag H.M. (1996). Comorbidity (psycho)analysed. British Journal of Psychiatry 168, Suppl. 30, 120-125.

Weissman M.M., Klerman G.L., Markowitz J.S. \& Quellette M. (1989). Suicidal ideation and suicide attempts in panic disorder and attacks. New England Joumal of Medicine 321, 1209-1214.

Wesner R.B. (1990). Alcohol use and abuse secondary to anxiety. Psychiatric Clinics of North America 13,699-713.

Wittchen H.U. (1994). Reliability and validity studies of the 
WHO-Composite International Diagnostic Interview (CIDI): A critical review. Journal of Psychiatric Research 28, 57-84.

Wittchen H.U. (1996). Critical issues in the evaluation of comorbidity, British Journal of Psychiatry 168, Suppl. 30, 126-132.

Wittchen H.U. \& Beloch E. (submitted for publication). The impact of social phobia on quality of life. Clinical Psychopharmacology.

Wittchen H.U. \& Essau C.A. (1989). Comorbidity of anxiety disorders and depression: does it affect course and outcome? Journal of Psychiatry and Psychobialogy 4, 315-323.

Wittchen H.U. \& Perkonigg A. (submitted for publication). Epidemiologie psychischer Störungen. Grundlagen, Häufigkeit, Risikofaktoren und Konsequenzen. In Enzyklopädie der Psychologie (ed. K. Hahlweg und A. Ehlers A). Hogrefe: Göttingen.

Wittchen H.U. \& von Zerssen D. (ed.) (1987). Verläufe behandelter und unbehandelter Depressionen und Angststörungen. Eine klinisch-psychiatrische und epidemiologische Verlaufsuntersuchung. Springer: Berlin.
Wittchen H.U. \& Vossen A. (1995). Implikationen von Komorbidität bei Angststörungen. Ein kritischer Uberblick. Verhaltensther Prax Forsch Perspekt 5, 120-133.

Wittchen H.U., Essau C.A. \& Krieg J.C. (1991). Anxiety disorders: Similarities and differences of comorbidity in treated and untreated groups. British Journal of Psychiatry 159, Suppl. 12, 23-33.

Wittchen H.U., Essau C.A., von Zerssen D., Krieg C.J. \& Zaudig M. (1992). Lifetime and six-month prevalence of mental disorders in the Munich Follow-up Study. European Archives of Psychiatry and Clinical Neuroscience 241,247-258.

Wittchen H.U., Perkonigg A. \& Reed V. (1996). Comorbidity of mental disorders and substance use disorders. European Addiction Research 2, 36-48.

World Health Organization (1991). ICD-10, Chapter V, Mental and Behavioral Disorders (Including Disorders of Psychological Development). Diagnostic Criteria for Research, Draft for Field Trials. World Health Organization: Geneva. 